\title{
BUCKLING EXPERIMENTS OF CRACKED AXIALLY COMPRESSED CONES
}

\section{O. IFAYEFUNMI}

Fakulti Teknologi Kejuruteraan Mekanikal dan Pembuatan, Universiti Teknikal Malaysia Melaka, Melaka, Malaysia

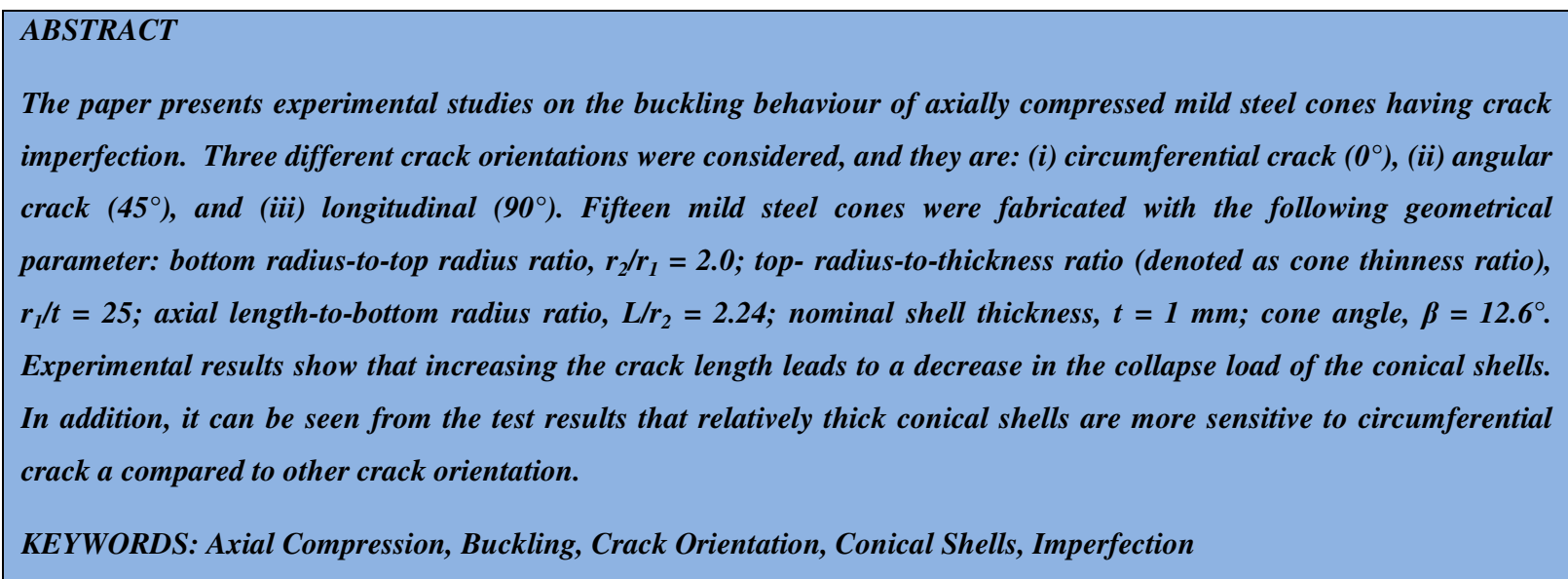

Received: Jun 06, 2020; Accepted: Jun 26, 2020; Published: Jul 30, 2020; Paper Id.: IJMPERDJUN2020539

\section{INTRODUCTION}

Thin-walled shell structures such as conical shells have been in use for many years in major engineering applications. As an example, (i) they are used as launcher vehicle system in many aeronautical applications, (ii) they are used to connect two or more cylinders with different diameter etc. Because conical shells are subjected to several loading application during their useful life, instability has been one of the primary design considerations for such shell structures. Over the years, it is generally believed that the presence of imperfection can lead to loss of instability of conical shells structures. This technical difficulty has sprawn several research investigations on the imperfection sensitivity of conical shells subjected to several loading. References [1-3] presents compilations of past studies on imperfection sensitivity of conical shells, where cones under the influence of several imperfection types such as eigenmode imperfections [4 - 8], dimple imperfections [9 - 15], uneven geometry (such as shape or length) imperfections [16 - 18], boundary condition imperfections [19 - 20] and crack imperfections [21] have been studied.

In Refs [4 - 8], eigenmode shape obtained from linear buckling analysis is superimposed on the perfect shape of shell. However, this form of imperfection has generated a lot of debate in recent time where it was argued that this imperfection type is not realistic in real life situation. One of the most realist forms of imperfection is the dimple imperfection in the form of single or multiple perturbation load imperfections as discussed in Refs [9 - 15]. While Refs [9 - 13] concentrate on the influence of the Single Perturbation Load imperfection (SPLA) on the buckling load of the conical shells. A ref [14 - 15] on the other hand was devoted to multiple perturbation load imperfection (MPLA). According to Refs [16 -18], the effect of manufactured induced imperfection such as uneven length on the load carrying capacity of cone is equally significant. In the paper, uneven length in the form of sinusoidal, triangular, and square waves was employed. The severity of effect of radial edge displacement 
constraints on the buckling load for stiffened conical shells subjected to axial compression was presented in Ref. [20]. However, for axially compressed cone with crack imperfection, only little information is available in the open literature. Ref. [21] presents numerical investigation into the buckling behaviour of cracked aluminium conical frusta subjected to axial compression concentrating on the influence of crack length and crack orientation. This paper aims to complement the work of Ref. [21] by providing more experimental data on the influence of crack amplitude and crack orientation on the load carrying capacity of relatively thick steel cones which typically fails within the elastic-plastic region.

\section{MATERIAL AND METHOD - EXPERIMENTATION}

Fifteen conical specimens (two perfect and thirteen cracked conical shells) were fabricated from $1 \mathrm{~mm}$ mild steel plate and axially compressed by a horizontal and rigid plate, moving downwards (see Figure 1). Crack of different orientation, $\theta$, was introduced to the cone and is varied from $0^{\circ}$ (circumferential crack), $45^{\circ}$ (angular crack) and $90^{\circ}$ (longitudinal crack) for several percentages of the crack length-to-axial length of the cone (i.e. 5\%, 10\%, 15\%, 20\%, 25\% and 50\%). The crack is located at the centre of the cone's meridional surface.

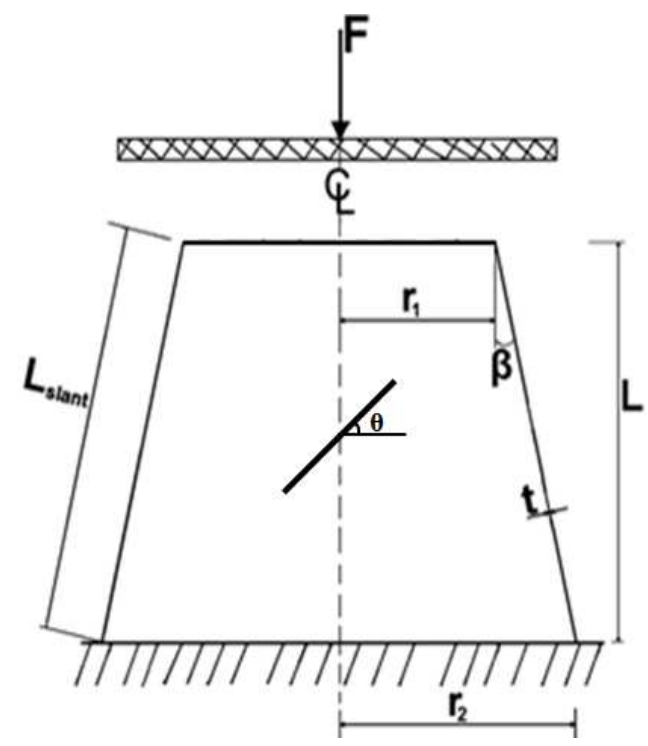

Figure 1: Geometry of Cone having Crack Imperfection Subjected to Axial Compression.

The manufacturing process of the conical shells is as followed. First, water jet cutting machine was used to cut the specimens into desired dimensions. Next, a conventional rolling machine was used to roll the sample into a conical shape. The joining of the neighbouring seam of rolled cones was achieved through Metal Inert Gas (MIG) welding method. The crack introduction method is different for each crack orientation. A pair of metal scissors was used to cut the rolled conical shells into desired crack length for conical shells having circumferential and angular crack before the welding process. While, for axial crack, the seam of the cone was left unwelded according to intended crack length. All cones were axially compressed through a universal testing machine.

Next, from the same mild steel plate used for specimens manufacturing, three pairs of flat tensile coupons were cut in the horizontal and vertical direction. The tensile test was carried out to determine the material properties of the mild steel cone specimens. All the coupons were tested to failure using an Instron universal testing machine at the loading rate of $1 \mathrm{~mm} / \mathrm{min}$. The material properties obtained from the tensile test are as follow: (i) Young's Modulus, E = 233.30 GPa, (ii) yield stress based on $0.2 \%$ offset, $\sigma_{\mathrm{yp}}=223.93 \mathrm{MPa}$, (iii) Poisson's ratio, $v=0.3$, taken from the material datasheet. These material properties will be used for the accompanying numerical prediction of the experimental data. 
Before axial compressive testing, a series of measurement (i.e., diameter, wall thickness, axial length, slant length, crack dimensions) were carried out on all manufactured conical shells to examine the manufacture-induced imperfection. First, Vernier calliper was used to measure the inner and outer diameter of the cones at five equally spaced diameters of the top and bottom ends of cones. The average measured mid-surface diameters, $2 r_{1}$ and $2 r_{2}$, can be found in Table 1 . Next, both axial length, $\mathrm{L}$ and slant length, $\mathrm{L}_{\text {slant }}$ of all the manufactured cones were measured using a Vernier calliper and their average measurement can be found in columns 6 and 7 of Table 1.

Afterwards, a micrometer screw gauge was used to measure wall thickness at eleven equidistant points along the cone's longitudinal surface. A similar measurement was carried out along the cone's circumference at $36^{\circ}$ apart, resulting in 11 x $9=99$ measuring points. Table 2 provides the thickness measured data for all the specimens. Lastly, the crack length and width on each specimen were measured through an inverted microscope. Table 3 shows the average measurement of each crack dimensions. The crack length-to-axial length ratio was denoted as crack percentage. The axial collapse test was carried out on all fifteen specimens using Instron testing machine at the loading rate of $1 \mathrm{~mm} / \mathrm{min}$, which is like the previous tensile testing's rate. The specimens top and bottom ends were respectively covered with rigid plates to restrict the movement of the cone top and bottom ends during the experiment, hence providing necessary boundary condition. The machine controller records the load-carrying capacity and the corresponding compression displacement of each specimen. Figure 2 presents typical experimental set up for this study as exemplified for specimen 1.

Table 1: Measurement of Cone Angle, Diameters, Axial Length, Slant Length, and Wall Thickness for all Tested Cones

\begin{tabular}{|c|c|c|c|c|c|c|}
\hline \multirow{2}{*}{ Specimen } & \multirow{2}{*}{ Crack Angle $\left({ }^{\circ}\right)$} & \multirow{2}{*}{$\mathbf{B}\left({ }^{\circ}\right)$} & $\mathbf{2 r}_{\mathbf{1}}$ & \multicolumn{2}{|c|}{$\mathbf{2 r}_{\mathbf{2}}$} & \multicolumn{4}{|c|}{$\mathbf{L}$} & $\mathbf{L}_{\text {slant }}$ \\
\cline { 4 - 7 } & & & & \multicolumn{4}{|c|}{} \\
\hline 1 & - & 11.63 & 50.37 & 99.18 & 112.52 & 114.88 \\
\hline 2 & - & 10.95 & 50.64 & 100.16 & 112.66 & 114.75 \\
\hline 3 & 90 & 11.10 & 50.32 & 99.92 & 112.71 & 114.86 \\
\hline 4 & 90 & 11.23 & 50.04 & 99.87 & 112.66 & 114.86 \\
\hline 5 & 90 & 11.03 & 49.60 & 99.56 & 112.58 & 114.70 \\
\hline 6 & 90 & 10.62 & 50.21 & 99.81 & 112.47 & 114.43 \\
\hline 7 & 90 & 10.65 & 50.31 & 99.53 & 112.37 & 114.34 \\
\hline 8 & 0 & 10.78 & 49.89 & 99.62 & 112.37 & 114.39 \\
\hline 9 & 0 & 10.75 & 49.84 & 99.21 & 112.46 & 114.47 \\
\hline 10 & 0 & 10.43 & 49.80 & 99.60 & 112.48 & 114.37 \\
\hline 11 & 0 & 10.75 & 50.14 & 99.49 & 112.47 & 114.48 \\
\hline 12 & 45 & 10.86 & 50.55 & 99.52 & 112.39 & 114.44 \\
\hline 13 & 45 & 10.78 & 50.20 & 99.88 & 112.36 & 114.38 \\
\hline 14 & 45 & 11.07 & 50.35 & 99.32 & 112.30 & 114.43 \\
\hline 15 & 45 & 10.49 & 50.60 & 99.35 & 112.44 & 114.35 \\
\hline
\end{tabular}


Table 2: Wall Thickness Measurement of all Specimens

\begin{tabular}{|c|l|c|c|c|c|}
\hline \multirow{2}{*}{ Model } & \multirow{2}{*}{ Crack Angle } & $\mathbf{t}_{\max }$ & $\mathbf{t}_{\min }$ & $\mathbf{t}_{\text {ave }}$ & \multirow{2}{*}{$\mathbf{t}_{\text {std }}$} \\
\cline { 3 - 5 } & & \multicolumn{3}{|c|}{$(\mathbf{m m})$} & \\
\hline 1 & - & 0.97 & 0.96 & 0.967 & 0.00262 \\
\hline 2 & - & 0.97 & 0.97 & 0.968 & 0.00112 \\
\hline 3 & Axial & 0.98 & 0.96 & 0.968 & 0.00228 \\
\hline 4 & Axial & 0.98 & 0.97 & 0.969 & 0.00313 \\
\hline 5 & Axial & 0.97 & 0.96 & 0.967 & 0.00192 \\
\hline 6 & Axial & 0.97 & 0.96 & 0.967 & 0.00157 \\
\hline 7 & Axial & 0.97 & 0.96 & 0.967 & 0.00168 \\
\hline 8 & Circumferential & 0.97 & 0.96 & 0.967 & 0.00186 \\
\hline 9 & Circumferential & 0.97 & 0.96 & 0.968 & 0.00148 \\
\hline 10 & Circumferential & 0.97 & 0.97 & 0.968 & 0.00118 \\
\hline 11 & Circumferential & 0.97 & 0.97 & 0.968 & 0.00095 \\
\hline 12 & Angular & 0.97 & 0.97 & 0.967 & 0.00118 \\
\hline 13 & Angular & 0.97 & 0.96 & 0.968 & 0.00126 \\
\hline 14 & Angular & 0.97 & 0.96 & 0.968 & 0.00118 \\
\hline 15 & Angular & 0.97 & 0.97 & 0.968 & 0.00103 \\
\hline
\end{tabular}

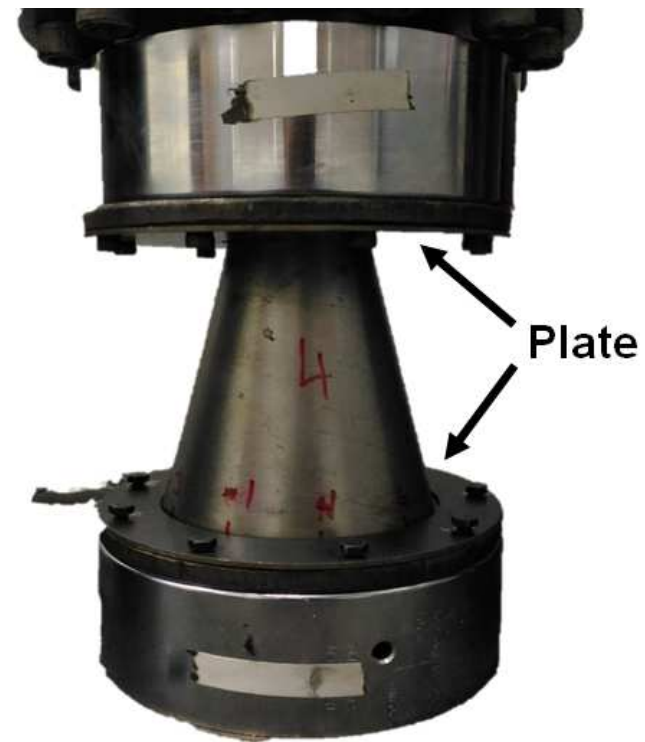

Figure 2: Experimental Setup for Axial Testing for Specimen 1.

\section{RESULTS AND DISCUSSIONS}

Experimental results for fifteen axially compressed perfect and cracked conical shells can be found in Table 3. It was clear that crack introduction can reduce the load-carrying capacity of the perfect conical shell. Figure 3 depicted the plot of experimental collapse load for all tested cones. It can be observed that the buckling load of axially compressed conical shell with crack imperfection is strongly dependent on the crack length. Similar to those reported in the past literature [21] for cones. A gradual drop is perceived as the crack percentage increases from 5\% to 50\%. However, a minimal difference between each crack orientation is also noticed. 


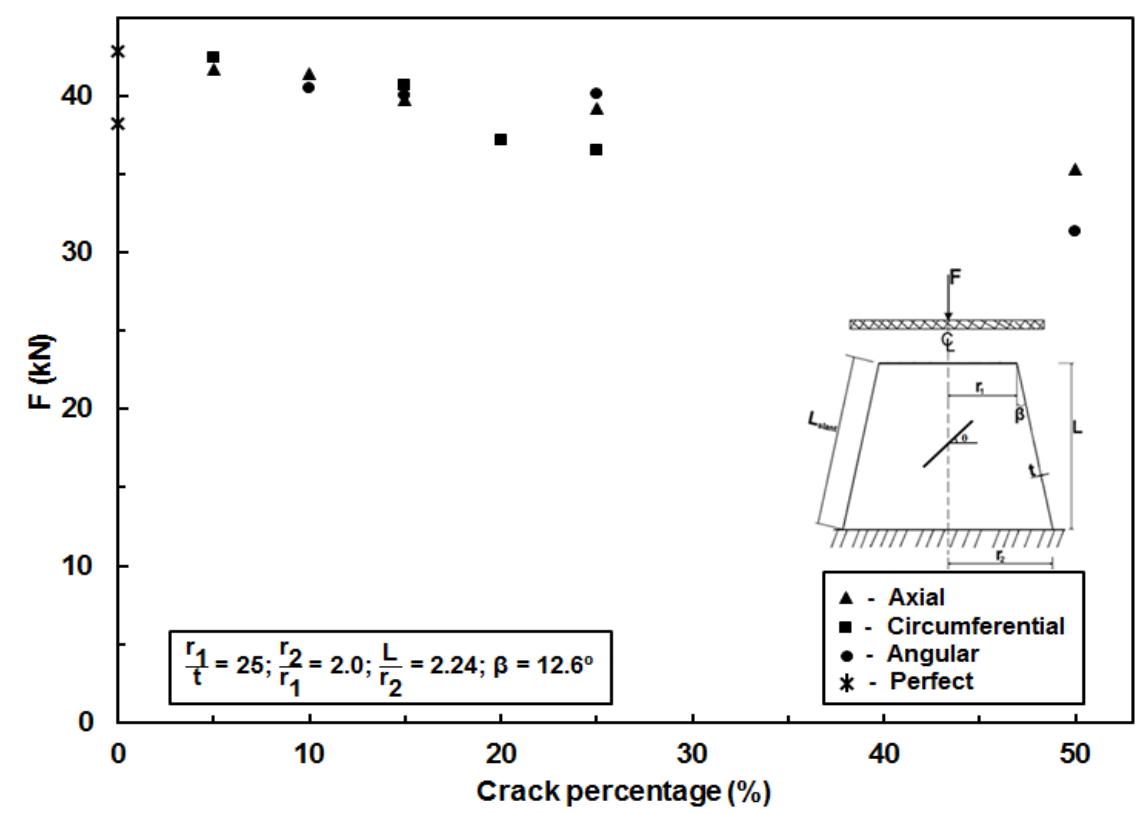

Figure 3: Experimental Axial Load Against the Crack Percentage of all Tested Cones.

The most substantial reduction of load-carrying capacity from the perfect cone (specimen 1) is $27 \%$ for specimen 15 having an angular crack. The corresponding value of buckling load is provided in Table 3. Figure 4 presents the plot of collapse load against axial shortening for cracked cones with 25\% crack (specimen 6, specimen 11 and specimen 14) for each crack orientation. The load-deflection curve is linear up till collapse loads and in the post-collapse region, a smooth fall of the load-deflection curve is observed. From Figure 4, conical shells having circumferential crack records the most detrimental effect on the collapse load. A local buckling preceding global buckling can be seen in the plot for conical shell having an angular crack.

Table 3: Buckling Load of the Cracked Conical Shell (Exptl $\equiv$ Experimental)

\begin{tabular}{|c|c|c|c|c|c|}
\hline \multirow[t]{2}{*}{ Specimen } & $\begin{array}{l}\text { Crack } \\
\text { length }\end{array}$ & $\begin{array}{l}\text { Crack } \\
\text { width } \\
\end{array}$ & \multirow{2}{*}{$\begin{array}{c}\text { Crack } \\
\text { percentage } \\
(\%)\end{array}$} & \multirow{2}{*}{$\begin{array}{c}\text { Crack } \\
\text { orientation } \\
\left({ }^{\circ}\right)\end{array}$} & \multirow{2}{*}{$\begin{array}{c}\text { Exptl } \\
\text { Collapse } \\
\text { load }(k N)\end{array}$} \\
\hline & \multicolumn{2}{|c|}{$(\mathrm{mm})$} & & & \\
\hline 1 & - & - & 0 & - & 42.865 \\
\hline 2 & - & - & 0 & - & 38.260 \\
\hline 3 & 5.73 & 0.183 & 5 & 90 & 41.774 \\
\hline 4 & 11.47 & 0.049 & 10 & 90 & 41.495 \\
\hline 5 & 17.21 & 0.204 & 15 & 90 & 39.766 \\
\hline 6 & 28.69 & 0.228 & 25 & 90 & 39.249 \\
\hline 7 & 57.38 & 0.238 & 50 & 90 & 35.370 \\
\hline 8 & 11.78 & 0.015 & 5 & 0 & 42.517 \\
\hline 9 & 35.35 & 0.066 & 15 & 0 & 40.758 \\
\hline 10 & 47.13 & 0.056 & 20 & 0 & 37.166 \\
\hline 11 & 58.91 & 0.210 & 25 & 0 & 36.518 \\
\hline 12 & 11.47 & 0.121 & 10 & 45 & 40.537 \\
\hline 13 & 17.21 & 0.113 & 15 & 45 & 40.032 \\
\hline 14 & 28.69 & 0.044 & 25 & 45 & 40.196 \\
\hline 15 & 57.38 & 0.073 & 50 & 45 & 31.376 \\
\hline
\end{tabular}




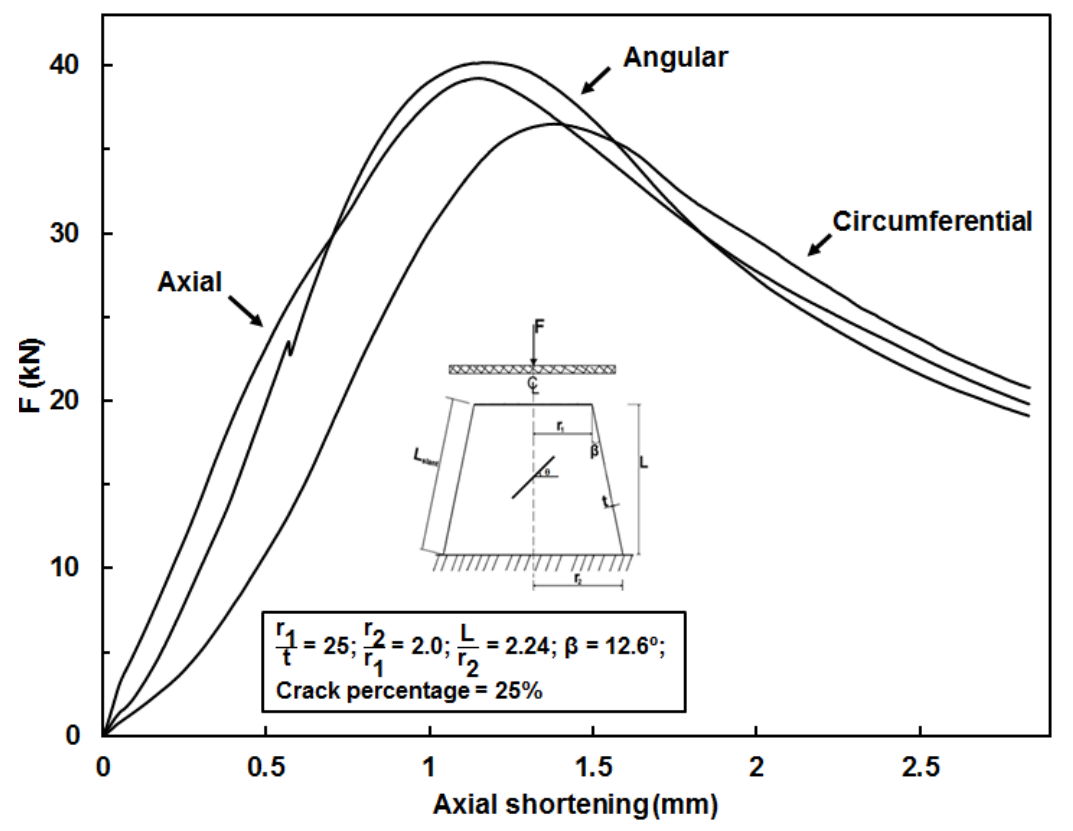

Figure 4: Experimental Axial Load Versus Axial Shortening for Cracked Cones with Different Crack Orientation Subjected to Axial Compression.

Figure 5 presents the plot of experimental collapse load versus their corresponding axial shortening for conical shells with axial crack imperfection. Similar plots for imperfect cones with circumferential crack and angular crack are presented in Figure 6 and Figure 7, respectively. It is apparent that increasing the crack length on the cone results in an increase of cone sensitivity towards imperfection regardless of the crack orientation. As an example, cones with circumferential crack imperfection, as the crack percentage gradually rise from $0 \%$ to $25 \%$, the buckling strength of the cracked cones reduced to $10.5 \%$ from the average buckling strength of the perfect cones. Similarly, for cones with axial and angular crack imperfection, as the crack percentage increases from $0 \%$ to $50 \%$, the buckling strength of the cone is decreased to $14 \%$ and $25.5 \%$ respectively. From Table 3, a considerably small crack percentage has little to none effect on the decline of the buckling strength of the conical shell. This is true for the case of conical shells as reported in Ref. [21].

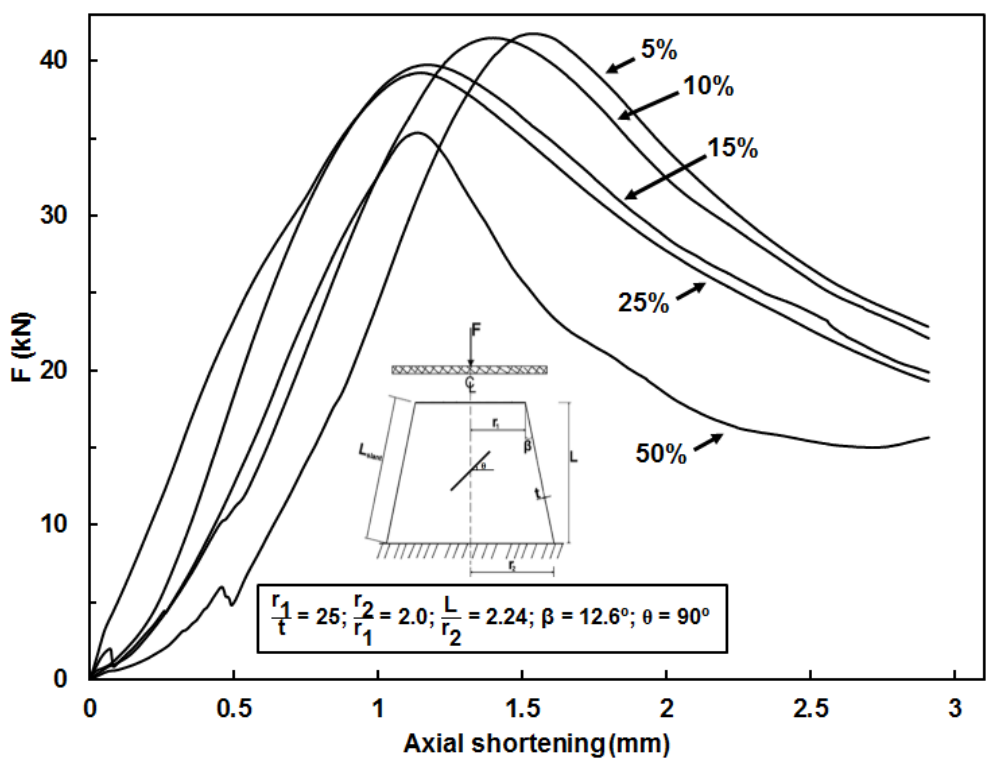

Figure 5: Experimental Axial Load against Axial Shortening for Conical Shells having Axial Crack. 


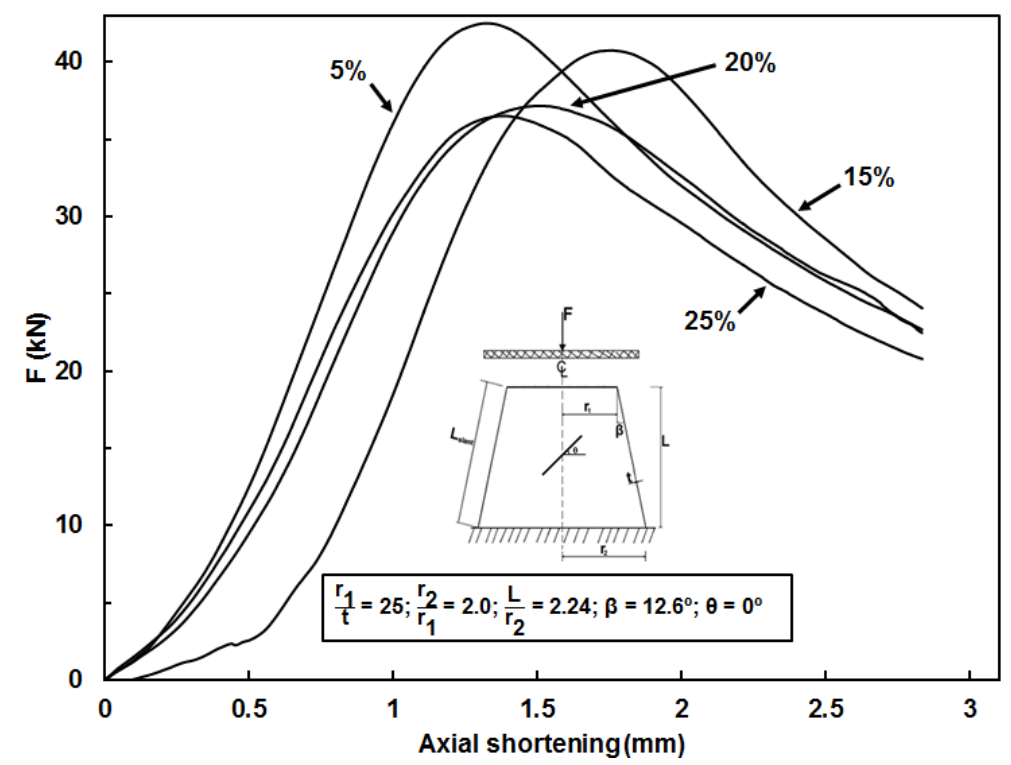

Figure 6: Experimental Axial Load against Axial Shortening for Conical Shells having Circumferential Crack.

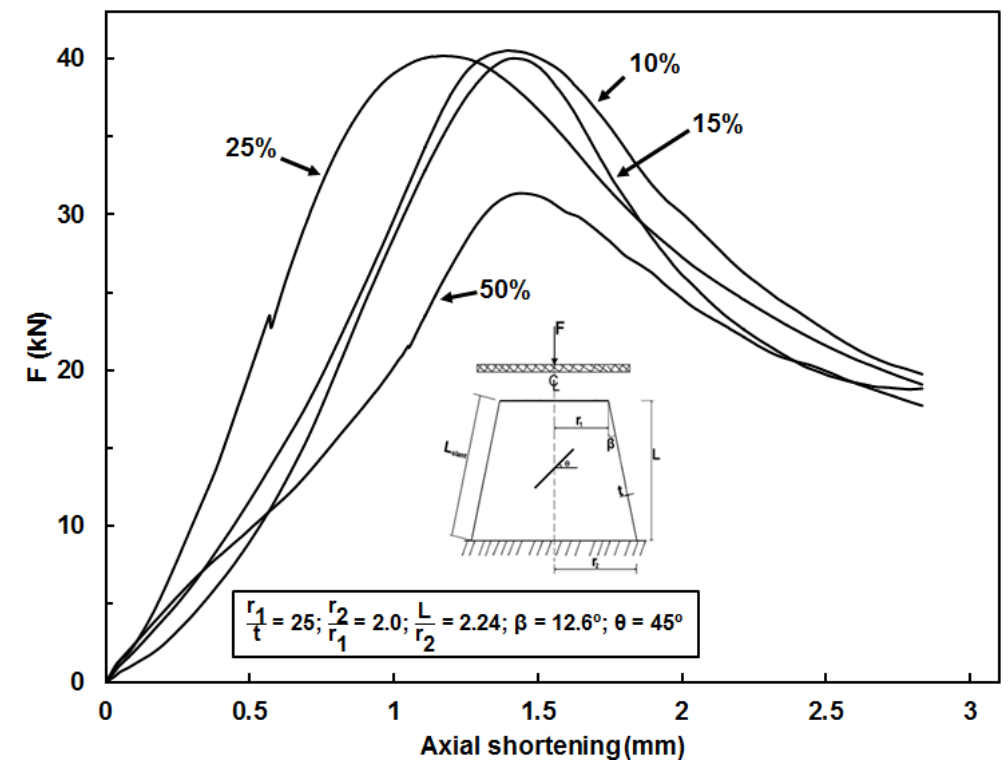

Figure 7: Experimental Axial Load against Axial Shortening for Conical Shells having Angular Crack.

\section{CONCLUSIONS}

This paper presents experimental investigation into the buckling behaviour of relatively thick steel conical shells having crack imperfection with different crack amplitude subjected to axial compression. Three different crack orientations were discussed in the paper i.e., circumferential crack $\left(0^{\circ}\right)$, angular crack $\left(45^{\circ}\right)$, and longitudinal $\left(90^{\circ}\right)$. The experimental results confirm that conical shell having circumferential crack orientation recorded the lowest buckling load, like what was reported in Ref. [21]. Furthermore, for any given crack orientation, it can be concluded that as the crack amplitude increases, the load carrying capacity of the cone decreases. 


\section{ACKNOWLEDGEMENT}

The author would like to acknowledge the financial support received from Universiti Teknikal Malaysia Melaka (UTeM) and the Ministry of Education Malaysia under Fundamental Research Grant Scheme FRGS/2018/FTKMP-CARE/F00386.

\section{REFERENCES}

1. Ifayefunmi, O., \& Blachut, J. (2018). Imperfection sensitivity: a review of buckling behavior of cones, cylinders and domes. Journal of Pressure Vessel Technology, Transaction of ASME, 140, 050801-1-050801-8.

2. Ifayefunmi, O. (2014). A survey of buckling of conical shells subjected to axial compression and external pressure. Journal of Engineering Science and Technology Review, 7, 182 - 189.

3. Ifayefunmi, O., FM Mahidan, and SH Wang. "Buckling of Cones with Imperfect Length Subjected to Axial Compression." International Journal of Mechanical and Production Engineering Research and Development (IJMPERD) 9. 4, Aug 2019, $219-228$

4. Goldfeld, Y., Sheinman,I., \& Baruch, M. (2003). Imperfection sensitivity of conical shells. AIAA Journal, 41, 517 - 524.

5. Chryssanthopoulos, M.K., Poggi, C., Spagnoli, A. (1998). Buckling design of conical shells based on validated numerical models. Thin-Walled Structures, 31, 257 - 270.

6. Ifayefunmi, O. "Plastic Buckling of Axially Compressed Cylinders: Correlation between Theory and Experiments." International Journal of Mechanical and Production Engineering Research and Development (IJMPERD) 9. 2, Apr 2019, $569-578$

7. Jabareen, M., Sheinman, I. (2006). Postbuckling analysis of geometrically imperfect conical shells. ASCE Journal of Engineering Mechanics, 132, 1326 - 1334.

8. Btachut, J. (2012). Interactive plastic buckling of cones subjected to axial compression and external pressure. Ocean Engineering, 48, 10-16.

9. Ifayefunmi, O., Błachut, J. (2011). The effect of shape, boundary, and thickness imperfections on plastic buckling of cones. In Proceedings of the International Conference on Ocean, Offshore and Arctic Engineering (OMAE 2011), vol. 2, OMAE201149055, pp.23-33, ASME, NY, USA (ISBN: 978-0-7918-4434-2).

10. Hussain, Mohammad Ahmed, and Ramancharla Pradeep Kumar. "Modelling of buried faults using applied element method." International Journal of Earthquake 3.1 (2013): 1-16.

11. Ifayefunmi, O., Błachut, J. (2013). Instabilities in imperfect thick cones subjected to axial compression and external pressure. Marine Structures, 33, 297-307.

12. Khakimova, R. et al. (2014). The single perturbation load approach applied to imperfection sensitive conical composite structures. Thin-Walled Structures, 84, 369-77.

13. Cooper, P., Dexter, C. (1974). Buckling of conical shell with local imperfections. NASA TM X-2991, pp. 1-21.

14. Shivaprakash, Y. M., et al. "Studies on mild steel particulates reinforced Duralumin composite fabricated through Powder metallurgy route." International Journal of Mechanical and Production Engineering Research and Development 9.2 (2019): 903-920.

15. Castro, S.G.P., Mittelstedt,C.F., Monteiro, A.C., Degenhardt, R., \& Ziegmann, G. (2015). Evaluation of non-linear buckling loads of geometrically imperfect composite cylinders and cones with the Ritz method. Composite Structures, 122, pp. $284-299$. 
16. Özyurt, E., Yllmaz, H., \& Tomek, P. (2018). Prediction of the influence of geometrical imperfection to load carrying capacity of conical shells under axial loading. Sigma Journal of Engineering and Natural Sciences, 36, pp. 11-20.

17. Ifayefunmi, O, Mahidan, F.M. Collapse of conical shells having single dimple imperfection under axial compression. ASME Journal of Pressure Vessel Technology, in print.

18. Hao, P., et al., (2016). Imperfection-insensitive design of stiffened conical shells based on equivalent multiple perturbation load approach. Composite Structures, 136, pp. 405-413.

19. Ifayefunmi, O., Mahidan, F.M., \& Maslan, M.H. (2020). Instability of conical shells with multiple dimples under axial compression. International Journal of Recent Technology and Engineering, 8, pp. 1022 - 1027.

20. Ifayefunmi, O., Mahidan, F.M., \& Wang, S.H. (2019). Buckling of cones with imperfect length subjected to axial compression. International Journal of Mechanical and Production Engineering Research and Development, 9, pp. 219 - 228.

21. Mahidan, F.M., Ifayefunmi, O. (2020). Further experiments on uckling of cones with imperfect length subjected to axial compression. International Journal of Mechanical and Production Engineering Research and Development, 10, pp. 65 - 76.

22. Ifayefunmi, O. Buckling of axially compressed cones with uneven length, International Journal of Materials and Product Technology, in print.

23. Spagnoli, A. (2003). Koiter circles in the buckling of axially compressed conical shells. International Journal of Solids and Structures, 40, pp. 6095-6109.

24. Chryssanthopoulos, M.K., Spagnoli, A. (1997). The influence of radial edge constraint on the stability of stiffened conical shells in compression. Thin-Walled Structures, 27, pp. 147-163.

25. Ali, D. (2013). Buckling of cracked conical frusta under axial compression. Research Journal of Recent Sciences, 2, pp. $33-39$.

\section{AUTHORS PROFILE}

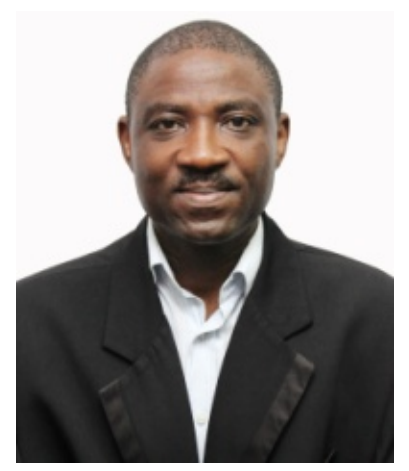

Olawale Ifayefunmi received his MSc (Eng) in Advanced Manufacturing Systems and Technology in 2006 and PhD in Mechanical Engineering in 2011 from The University of Liverpool, United Kingdom. He worked as Research Associate for six months in 2012 and as Honorary Research Fellow for two months in 2013 at The University of Liverpool. He was appointed Senior Lecturer at Faculty of Mechanical and Manufacturing Engineering Technology, Universiti Teknikal Malaysia Melaka in 2013. Whilst in the UK, he has developed unique expertise in experimental and computational mechanics. Initially he has worked on combined stability of conical shells - the theme directly relevant to offshore/underwater, petrochemical and energy industries. He then briefly moved to bioengineering field, and more recently he has expanded his expertise to burst failures of pressure vessels components. He has published more than 25 
papers in reviewed scientific journal and proceedings. His research interest include buckling of shells, structural integrity of pressure vessels components, impefection sensitivity of shell components. 